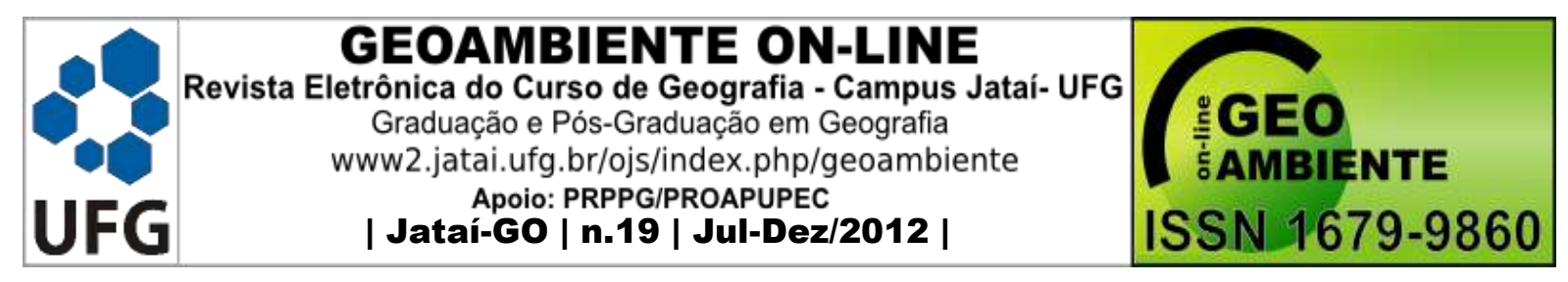

\title{
ANÁLISE MULTITEMPORAL DA COBERTURA DO SOLO DO MUNICÍPIO DE PONTA PORÃ, MATO GROSSO DO SUL, DE 1966 A 2006
}

\author{
Thalita Beatriz Antunes Klais ${ }^{1}$; Fabrício Bau Dalmas ${ }^{2}$; Giancarlo Lastoria ${ }^{3}$; Antonio \\ Conceição Paranhos Filho ${ }^{4}$
}

(1 - Universidade Federal de Mato Grosso do Sul - UFMS, Centro de Ciências Exatas e Tecnologia - CCET, Laboratório de Geoprocessamento para Aplicações Ambientais. Campus Universitário, Campo Grande, MS. E-mail: thaliklais@yahoo.com.br, 2 - Universidade de São Paulo, Instituto de Geociências, Programa de Pós-Graduação em Recursos Minerais e Hidrogeologia, fbdalmas@usp.br, 3 -Universidade Federal de Mato Grosso do Sul - UFMS, Centro de Ciências Exatas e Tecnologia - CCET, g.lastoria@ufms.br, 4 - Universidade Federal de Mato Grosso do Sul, Programa de Pós-Graduação em Tecnologias Ambientais, Centro de Ciências Exatas e Tecnologia, antonio.paranhos@pq.cnpq.br)

\section{Resumo}

Neste trabalho avaliou-se a evolução do uso e ocupação do solo em Ponta Porã - MS no período compreendido entre 1966 e 2006, tendo como base o uso de geotecnologias e dados de sensoriamento remoto, permitindo o monitoramento ambiental dos processos antrópicos. Ponta Porã é cidade limítrofe a oeste com a República Federativa do Paraguai, formando uma conurbação internacional com Pedro Juan Caballero, isso confere a região vantagens relacionadas à logística e a boas condições para o desenvolvimento econômico. Para a análise multitemporal da cobertura do solo foram utilizadas as cartas topográficas do DSG/IBGE da década de 1960 e imagens de satélite Landsat de 1989 e 2006. Na classificação da cobertura do solo utilizou-se a legenda do Projeto CORINE. Entre 1966 e 1989 houve um decréscimo nas áreas ocupadas por áreas naturais de $24,15 \%$ para $15,94 \%$ da superfície do município e um acréscimo entre 1989 e 2006, para 18,83\%. Considerando o período total (1966 - 2006), a evolução do uso e ocupação do solo decorrente da ação antrópica permaneceu estável, pois houve apenas um decréscimo de 5,32\% de áreas naturais.

\footnotetext{
Artigo recebido para publicação em 07 de Dezembro de 2011 Artigo aprovado para publicação em 03 de Novembro de 2012
} 


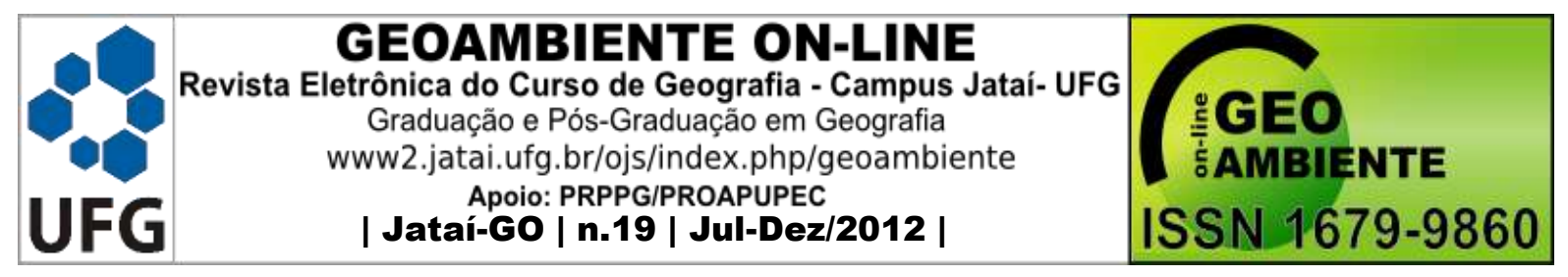

Palavras-chave: análise multitemporal, uso e ocupação do solo, sensoriamento remoto.

\section{Abstract \\ MULTITEMPORAL LAND COVER ANALYSIS OF PONTA PORÃ MUNICIPALITY, MATO GROSSO DO SUL STATE, BRAZIL, FROM \\ 1966 TO 2006}

This study evaluated the evolution of the use and occupation of Ponta Pora - MS from the period between 1966 and 2006, based on the use of geotechnologies and remote sensing data, enabling the monitoring of environmental anthropogenic processes. Ponta Pora is a city with a boundary to the west with the Federal Republic of Paraguay, forming an international conurbation with Pedro Juan Caballero, conferring advantages to the region related to logistics and good conditions for economic development. For the multitemporal analysis of land cover, topographic maps of the DSG / IBGE in the 1960's and Landsat satellite images from 1989 and 2006 were used. The CORINE project legend was used to classify the land cover. Between 1966 and 1989, there was a decrease in the areas occupied by natural areas from $24.15 \%$ to $15.94 \%$, and an increase between 1989 and 2006 to $18.83 \%$. Considering the whole period (1966 - 2006), the evolution of the use and occupation of the land caused by human action has remained stable as there was a decrease of only $5.32 \%$ in the extent of natural areas.

Key words: multi-temporal analysis, land use, remote sensing.

\section{Resumen}

\section{ANÁLISIS MULTITEMPORAL DE LA COBERTURA DE LA TIERRA EN LA CIUDAD DE PONTA PORÃ, MATO GROSSO DO SUL, ENTRE}

\section{Y 2006}

Este estudio evalúa la evolución del uso y ocupación del suelo en la ciudad de Ponta Porã (MS) entre 1966 y 2006, basándose en el uso de geotecnologias y datos de sensores remotos, permitiendo la monitorización ambiental de los procesos antropogénicos. Ponta Porã se encuentra ubicada en la frontera con la República del Paraguay, formando una conurbación internacional junto a Pedro Juan Caballero, por lo que la región posee ventajas relacionadas 


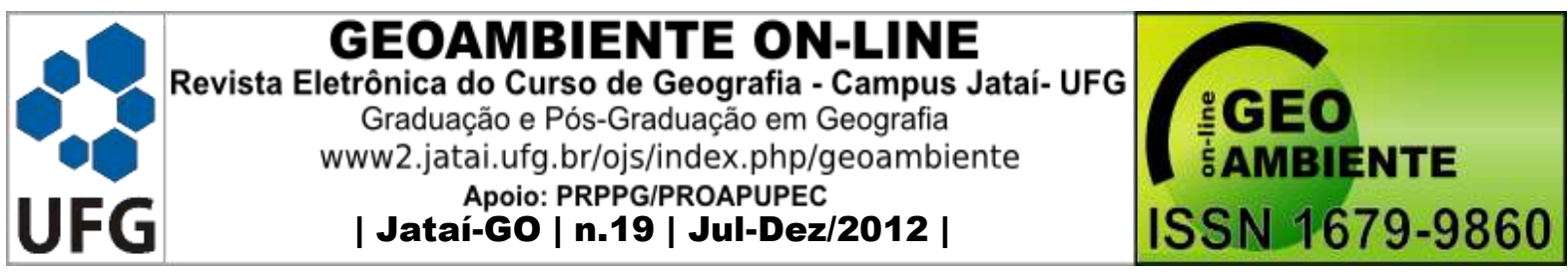

con la logística y las buenas condiciones para el desarrollo económico. Para el análisis multitemporal de la cobertura del suelo se utilizaron mapas topográficos del DSG / IBGE de la década de 1960 e imágenes de satélite Landsat de 1989 y 2006. En la clasificación de la cobertura del suelo fue usada la leyenda del proyecto CORINE. Entre 1966 y 1989 hubo una disminución en las zonas ocupadas por areas naturales, del 24,15\% al 15,94\% de la superficie de la ciudad y un aumento entre 1989 y 2006 al 18,83\%. Teniendo en cuenta todo el período (1966 - 2006), la evolución del uso y ocupación del suelo causada por la acción humana se ha mantenido estable debido a la disminución de las áreas naturales en un 5,32\%.

Palabras clave: análisis multitemporal, uso y cobertura del suelo, sensoriamento remoto.

\section{Introdução}

O constante uso do solo nem sempre leva em consideração os manejos mais adequados desse recurso, o que promove maior desgaste e empobrecimento do meio físico como um todo. De acordo com Carrijo (2005) a modificação da vegetação nativa compromete o habitat natural e a disponibilidade e qualidade dos recursos hídricos. Dessa forma, com o passar dos tempos, o homem vem procurando encontrar um ponto de equilíbrio entre o uso racional dos recursos naturais e da produtividade. Porém, em muitas áreas, os fatores econômicos prevalecem sobre a potencialidade do meio.

Para Santos et al. (2007), o estado atual de um meio natural não é o produto de impactos individuais independentes, mas o resultado de um conjunto de interferência que se propagam ao longo do tempo. A combinação de fatores de degradação presentes e passados é complexa, porém cada um deles pode ser visto como um fator de degradação, predominando em diferentes pontos, no tempo e no espaço e devem ser discutidos e traduzidos em cenários, os quais podem indicar os resultados futuros, apropriados ou inapropriados. Sendo assim, as paisagens passadas e presentes tem diferentes trajetórias possíveis e a tarefa de um planejador é concentrar os esforços nos pontos críticos que afetam essa trajetória numa ação preventiva.

Nessa visão, a estratégia é o acompanhamento da evolução temporal e espacial do uso do solo, dos recursos naturais e, principalmente, da cobertura vegetal. O trabalho de Grigio (2008) mostrou que através de uma análise multitemporal pode-se realizar projeções futuras através de modelo de simulações. Este autor destacou os pontos mais vulneráveis, dando recomendações de uso futuros para amenizar as transformações. 


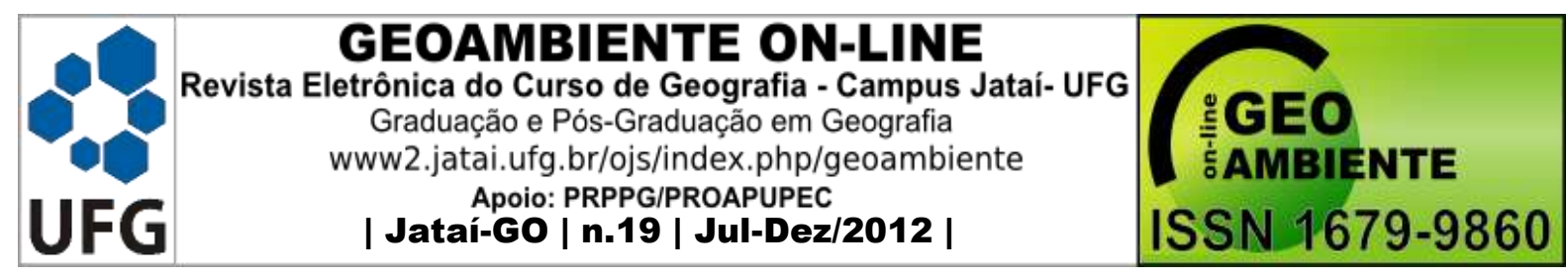

Neste contexto, o Sensoriamento Remoto constitui-se numa técnica de grande utilidade, pois permite em curto espaço de tempo a obtenção de uma grande quantidade de informações espaciais, espectrais e temporais (Grigio, 2008), sendo o Sistema de informações Geográficas (SIG) o ambiente ideal para integrar dados de natureza e escalas diversas (Paranhos Filho et al., 2008). As geotecnologias são compostas por várias ferramentas, a análise multitemporal é uma destas no estudo da evolução ambiental de uma área, pois estabelece comparações de uma mesma paisagem entre dois ou mais períodos auxiliando o monitoramento e/ou diagnóstico dessas regiões (Grigio, 2003; Oliveira, 2005).

A área de estudo deste projeto foi o Município de Ponta Porã, que abrigou a fazenda com a maior produção individual de soja do Brasil, entre as décadas de 1970 e 1980, propriedade do Grupo Itamarati, do Sr. Olacir de Moraes. Com o emprego de irrigação por meio de pivôs centrais, uso intensivo de capital, fertilizantes e defensivos, altos níveis de produtividade foram alcançados tanto nas culturas de soja como milho, trigo, algodão e culturas de menor expressão como feijão e ervilha (Bones, 2006).

A fazenda era considerada referência nacional e internacional para a agricultura em larga escala. Porém, problemas econômicos a levaram à falência, sendo então entregue ao Banco Itaú, que não teve interesse em continuar explorando o sistema produtivo praticado durante três décadas e, assim, ofertou a área ao Governo Federal em dezembro de 2000 para que fosse implantado um projeto de assentamento para famílias acampadas no Estado de Mato Grosso do Sul.

Como em Ponta Porã, a interferência do homem no meio ambiente e a utilização inadequada das terras vêm gerando, ao longo do tempo, a insustentabilidade dos recursos naturais. Os desmatamentos, exposição do solo às intempéries, intensa utilização de insumos e escoamento superficial geram impactos negativos decorrentes da erosão (Santos et al. 2007). Segundo Franco et al. (2002), a conservação dos solos por meio de políticas obrigatórias normalmente não atinge os objetivos. Por essa razão, é necessário estabelecer um sistema de conservação do solo, associado à observação do uso do solo na paisagem.

A aplicação de técnicas de Sensoriamento Remoto na análise dos impactos decorrentes de tais maneiras inadequadas de uso dos solos é imprescindível para a conservação do ambiente. De acordo com Grigio (2003), as análises multitemporais permitem o estudo da evolução ambiental de uma região desde o início da intensificação dos processos antrópicos. 


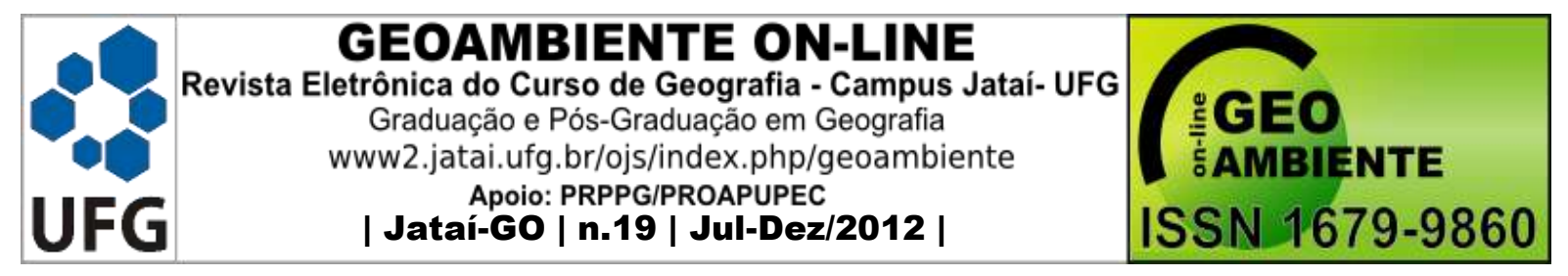

O objetivo desta pesquisa foi identificar, mapear e interpretar a evolução do uso e ocupação do solo do Município de Ponta Porã, no período de 1966 a 2006, através do Sensoriamento Remoto.

\section{Material e Métodos}

\section{1. Área de estudo}

A área de estudo é o município de Ponta Porã, localizado na porção sul do Estado de Mato Grosso do Sul, entre as coordenadas, UTM 591.732/708.400E, 7.607.260/7.481.883N, Fuso 21, datum Córrego Alegre (Figura 1).

A vegetação é caracterizada pelos campos limpos, formado por grandes áreas de gramíneas rasteiras, pastagens naturais, com Latossolos Vermelho Escuro predominando o Latossolo Roxo.

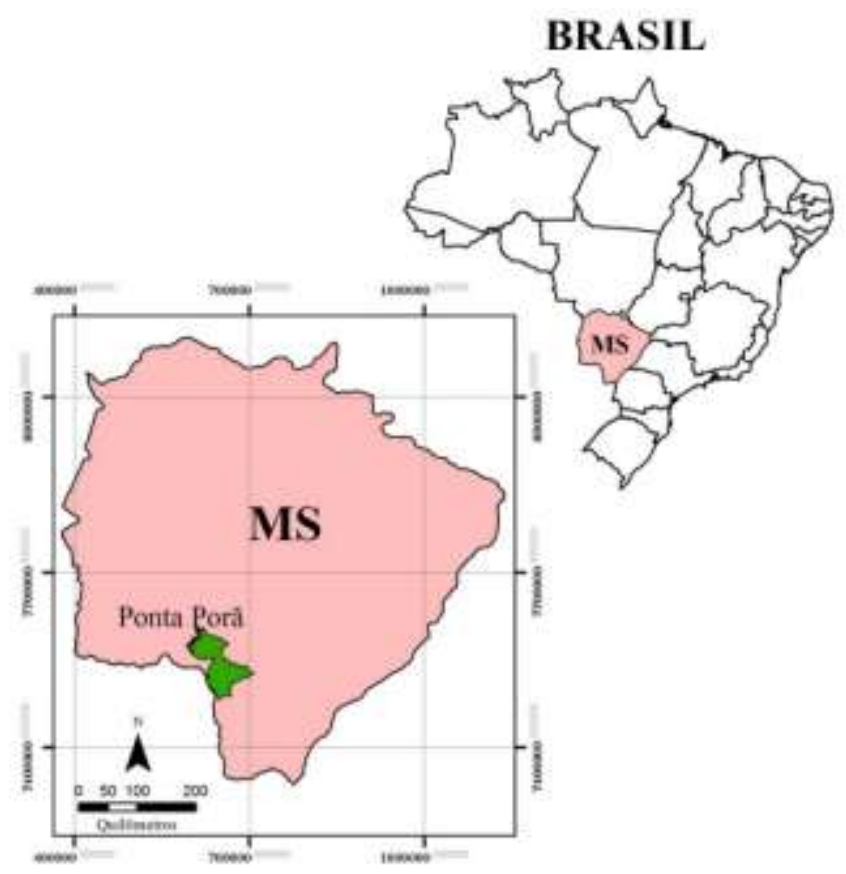

Figura 1. Localização do Município de Ponta Porã, Mato Grosso do Sul, Brasil.

\subsection{Uso do solo}




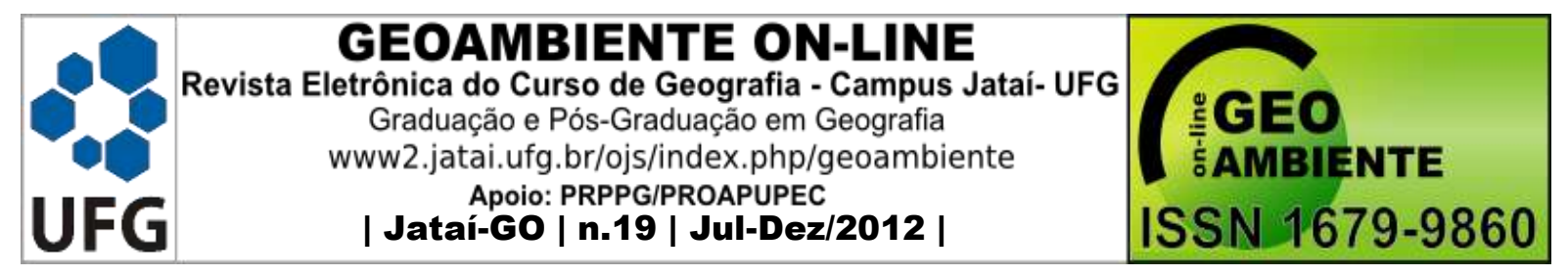

A caracterização do uso do solo no Município de Ponta Porã teve objetivo de correlacionar às formas de ocupação que obtiveram mudanças entre 1966 e 2006. A sua elaboração foi a partir dos seguintes materiais:

a) Uso das cartas topográficas, DSG/IBGE, de 1966, utilizando suas informações de cobertura do solo, em escala 1:100.000;

b) Classificação do uso do solo com as bandas 1, 2, 3, 4, 5 e 7 da imagem do sensor Landsat 5-TM do ano de 1989 e do ano de 2006, utilizando a legenda de cobertura do solo e projeto Coordination of Information on the Environment (CORINE);

c) Cruzamento da classificação do uso do solo de 1989 com o mesmo tipo de classificação para o ano de 2006.

\subsection{Cartas topográficas}

Para a formação do mosaico das cartas topográficas do DSG/IBGE (1:100.000), foi realizado o escaneamento, recorte e georreferenciamento destas cartas no programa Erdas Imagine (Erdas, 1997). Para a vetorização foi usado o programa Macromedia FreeHand (Macromedia, 2000) e para a quantificação e aplicação de seus dados foi utilizado uma extensão SIG para este programa, o Avenza MaPublisher (Avenza, 2001).

As cartas topográficas utilizadas foram: Antonio João (DSG, 1966a), Bocajá (DSG, 1966b). Boqueirão (DSG, 1966c), Campestre (DSG, 1966d), Dourados (DSG, 1966e), V Maracaju (DSG, 1971a), Ponta Porã (DSG, 1971b) e Vista Alegre (DSG, 1971c).

\subsection{Análise Multitemporal}

\subsubsection{Imagens de Satélite}

Os dados de Sensoriamento Remoto foram obtidos a partir das órbitas-ponto das imagens Landsat 5-TM (225-075, de 07/07/1989 e 06/07/2006, 225-076 de 06/07/2006 e 06/07/2006), na projeção UTM, Fuso 21, datum Córrego Alegre. As imagens foram georreferenciadas e classificadas segundo a legenda CORINE, utilizando o programa Erdas Imagine (Erdas, 1997). As cenas do sensor Landsat dos anos de 1989 e 2006 foram adquiridas no site do Instituto Nacional de Pesquisas Espaciais (INPE).

Foi realizado levantamento em campo de pontos estratégicos no Município de Ponta Porã com a utilização do GPS (Global Positioning System), além de um controle de campo 


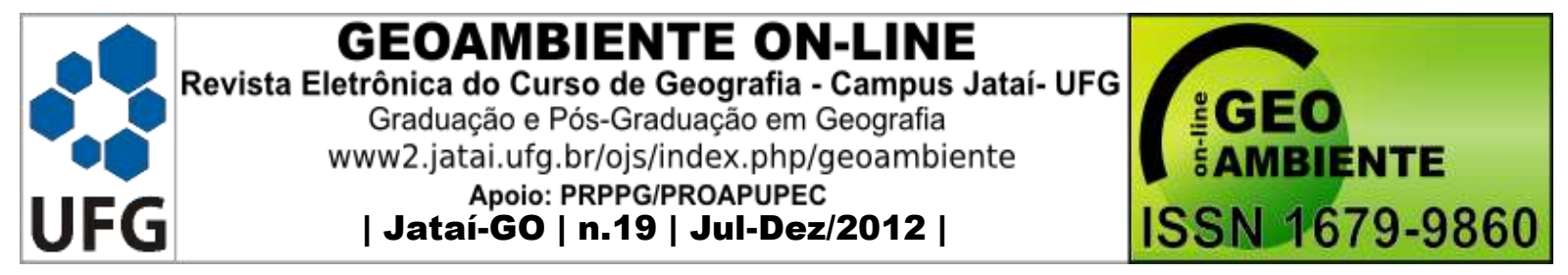

para averiguação das assinaturas espectrais que se encontram nas imagens de satélite. Durante o controle de campo foram percorridos mais de $500 \mathrm{~km}$ para avaliação do uso e ocupação do solo, resultando em 84 pontos de controle, em outubro de 2007.

\subsubsection{Classificação}

O tipo de classificação empregada foi a automática supervisionada. Essa se baseia na resposta espectral da imagem com uma seleção de áreas de treinamento fornecida ao sistema pelo usuário. As áreas de treinamento para a classificação da imagem de 2006 foram obtidas através de pontos de controle coletados na fase de campo efetuada em 2007. Essas mesmas áreas de treinamento constituíram a base para classificação da imagem de 1989.

\subsubsection{Cobertura do Solo}

Deve-se ter em mente que uma imagem reflete o estado da cobertura do solo apenas no momento da obtenção da imagem. Para se identificar o uso do solo, é necessária informação complementar, como outras imagens do mesmo local, em outras épocas, ou controle de campo (Paranhos Filho et al., 2008).

A legenda de cobertura utilizada na carta de uso do solo de 1989 é do Projeto CORINE (Corine, 1992 e Paranhos Filho, 2000), referência para a elaboração do Manual de Uso da Terra do Instituto Brasileiro de Geografia e Estatística (IBGE, 2006) e foi criada em 1985 pela Comunidade Européia com o objetivo de desenvolver um sistema de informação sobre o estado do ambiente europeu. Trata-se de informação nominal, exaustiva e sistematizada, numa nomenclatura de 44 classes, compatível com outros sistemas de classificação de uso/ocupação do solo em utilização. Essa mesma legenda foi usada para classificar a imagem de 2006. Dessa forma há uma equivalência entre as coberturas utilizadas, podendo ser feita a comparação entre os valores de área obtidos.

\section{Resultados}

A análise temporal e o cruzamento de mapas possibilitaram deduções diretas e pontuais sobre as mudanças do uso e ocupação do solo do Município de Ponta Porã e sobre o estádio de preservação de elementos que compõem o meio ambiente.

Durante a década de 1960, o povoamento e a ocupação dessa região estiveram relacionados com disputas e conflitos em torno da posse de terras, por esse motivo que, em 


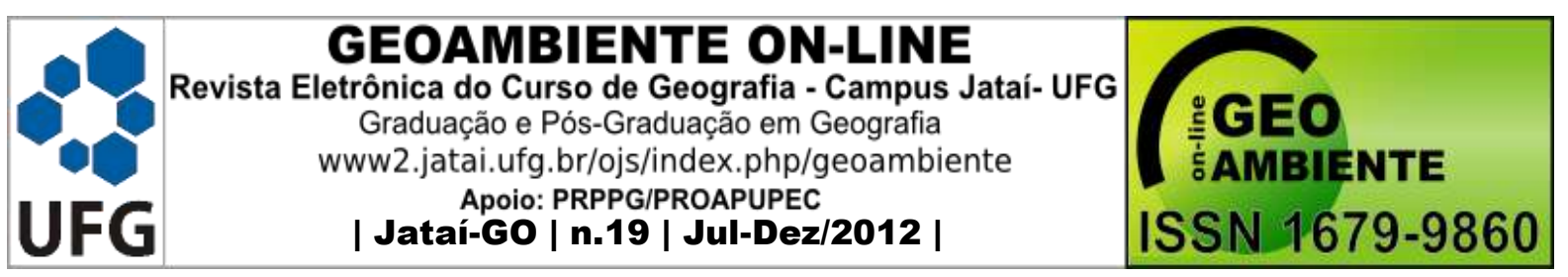

1966, 74,99\% da cobertura do solo eram compostas por campo, com somente $0,78 \%$ de áreas destinadas à agricultura. No mapa de cobertura do solo de 1966 (Figura 2) é possível visualizar que o município possuía 13,94\% de seu território composto por matas; 9,99\% de cerrados; $0,22 \%$ referente a lagos e rios e $0,07 \%$ de área urbana.

Pode-se classificar a área do Município de Ponta Porã em dois grandes grupos: áreas naturais (mata, cerrado, lagos e rios) e áreas antropizadas (agricultura, campo e urbano). Em 1966 as áreas naturais correspondiam a 24,15\% do território, enquanto os restantes $75,85 \%$ eram de áreas antropizadas A classificação das áreas em naturais ou antrópicas, em 1966, é visualizada na Figura 3.

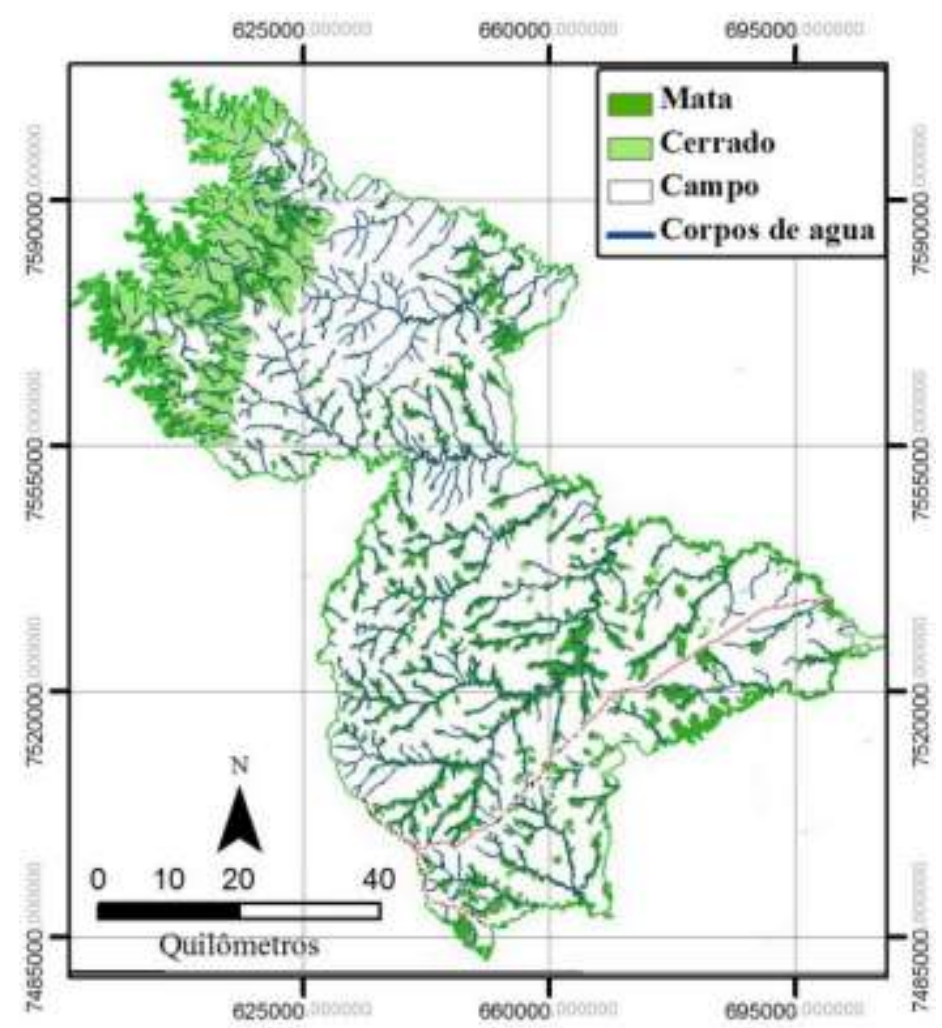

Figura 2. Cobertura do solo de Ponta Porã, 1966. 


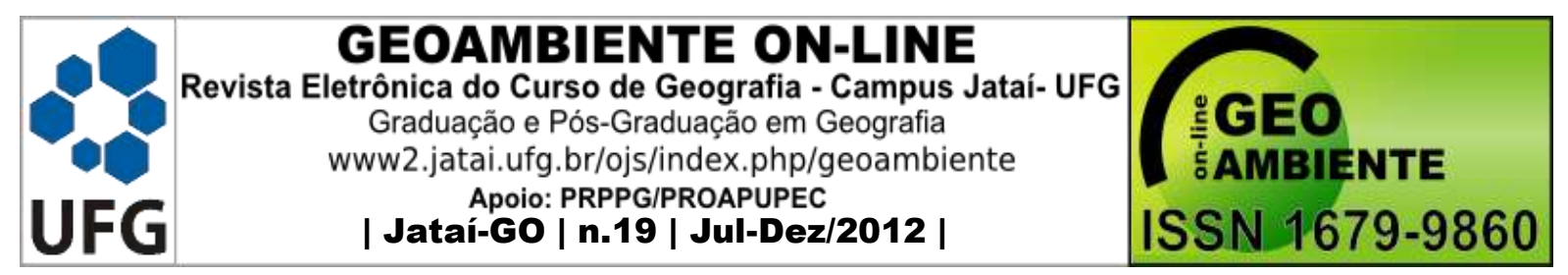

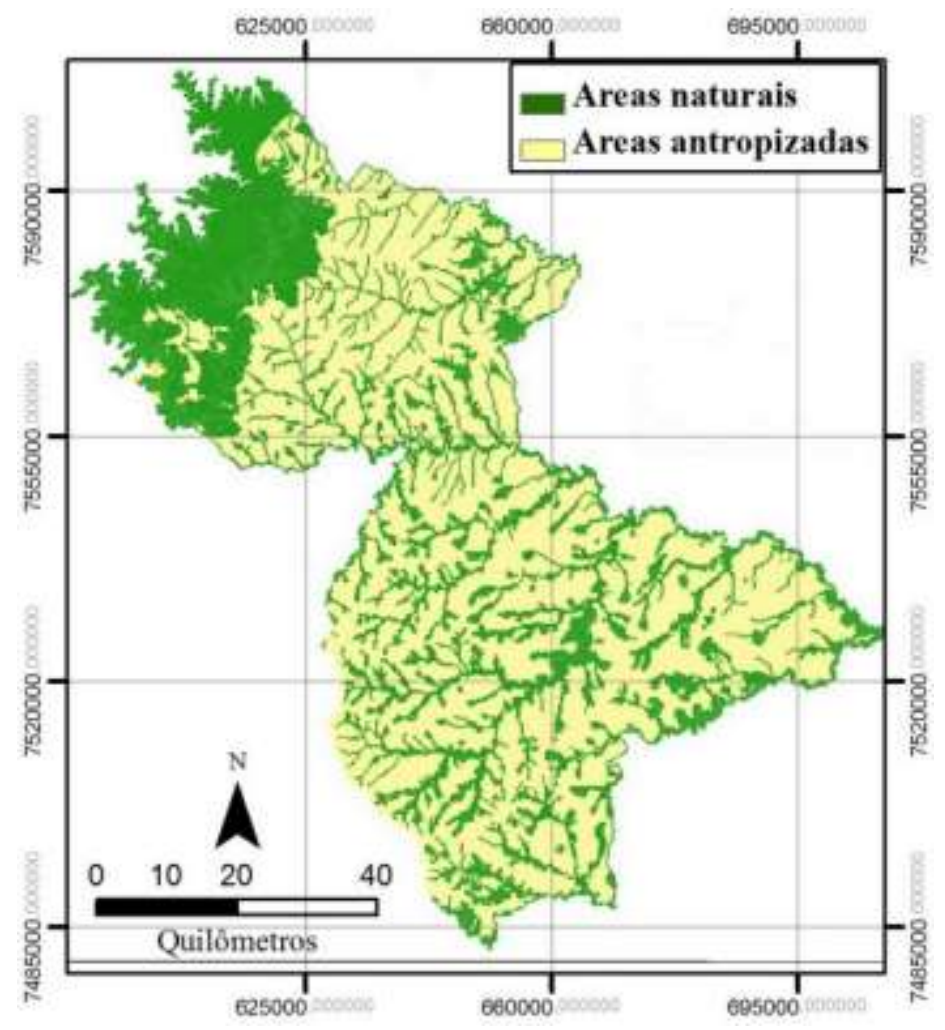

Figura 3. Áreas naturais e antropizadas de Ponta

Porã, 1966.

Nas décadas de 70 e 80 houve um novo fluxo migratório para Ponta Porã com a vinda de inúmeras famílias provenientes do Rio Grande do Sul e, assim, avanço da agricultura mecanizada associada especialmente à soja, trigo e milho. As mudanças mais marcantes, visualizadas na carta de uso do solo de 1989, foram o decréscimo da área de campo de $74,99 \%$ para $60,86 \%$, e um crescimento expressivo nas áreas destinadas à agricultura de 0,78\% para 22,73\% da área total do município (Figura 4). Durante o período compreendido entre 1966 e 1989 as áreas naturais foram reduzidas de 24,15\% para 15,94\%. Em contrapartida, as áreas antropizadas tiveram acréscimo de 75,85\% para 84,06\% (Figura 5). 


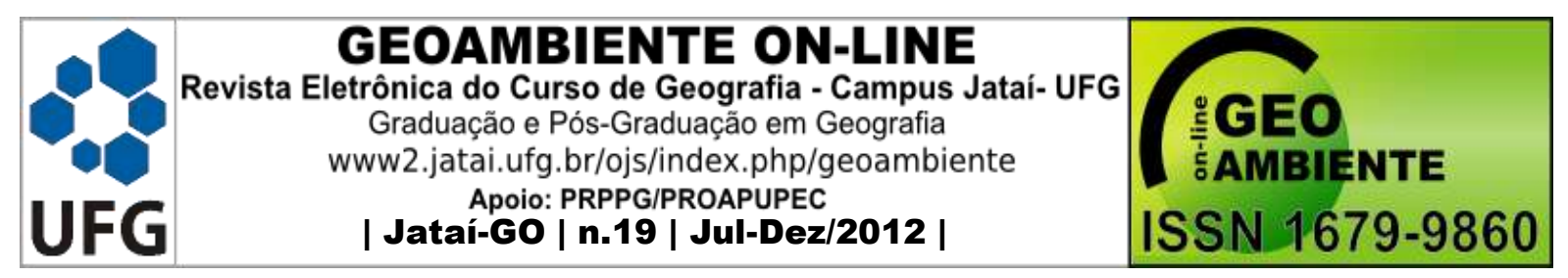

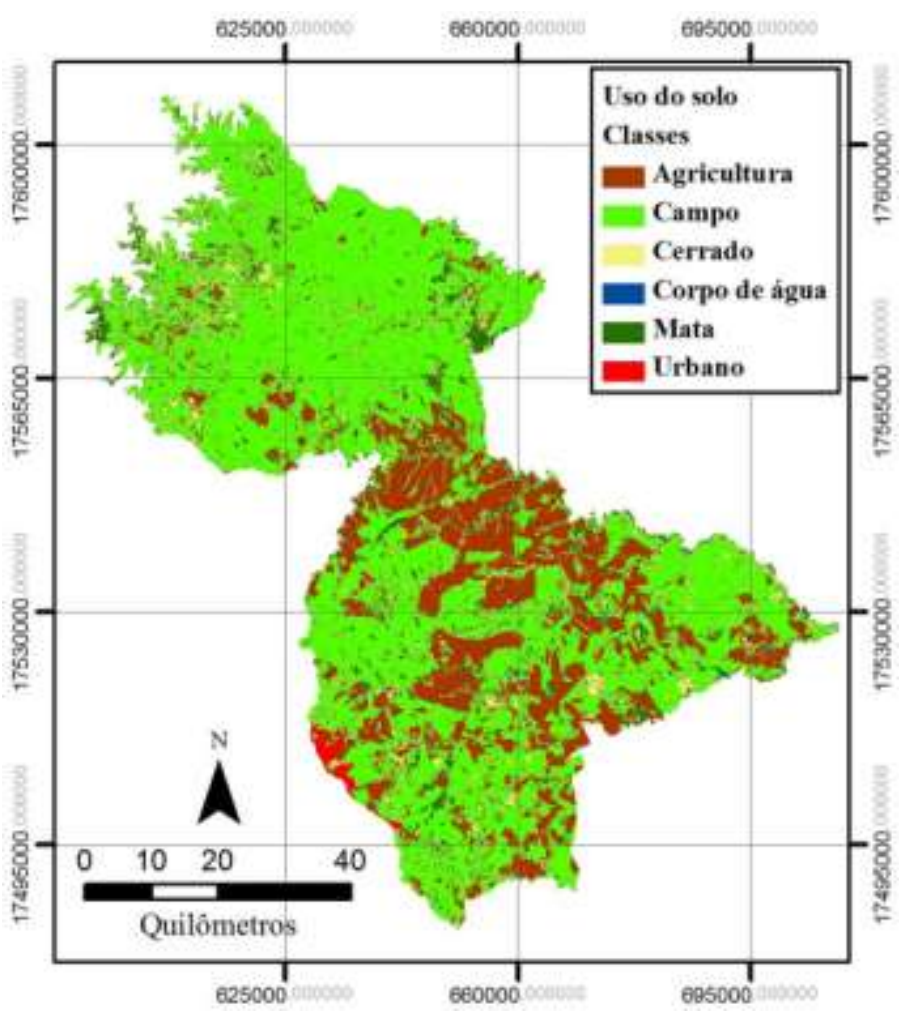

Figura 4. Cobertura do solo de Ponta Porã, 1989.

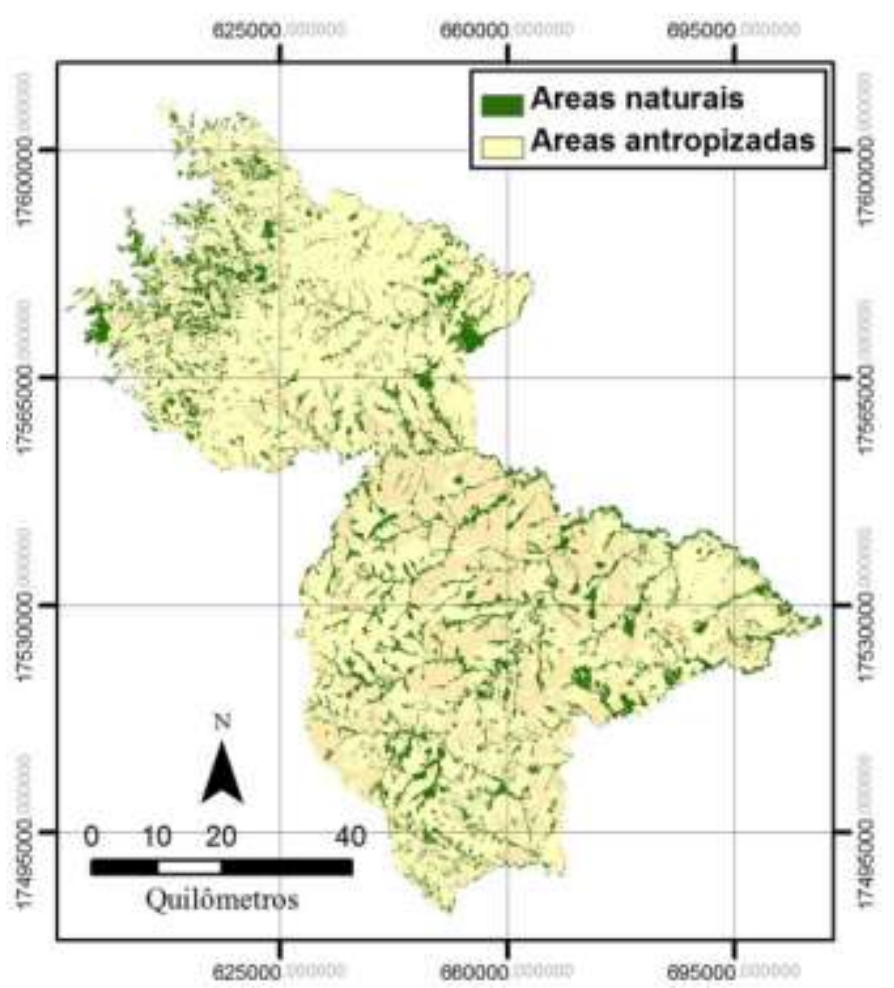

Figura 5. Áreas naturais e antropizadas de Ponta Porã, 1989. 


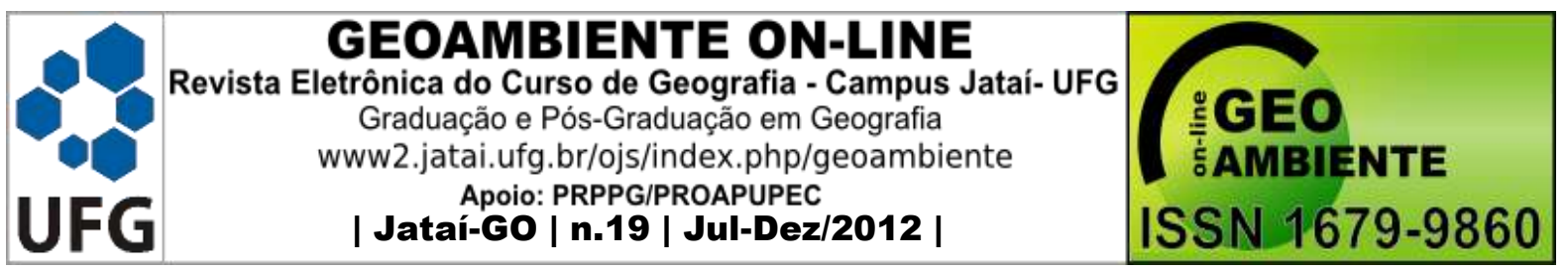

Entre 1989 e 2006 houve, novamente, decréscimo na área de campo de 60,86\% para $46,64 \%$ da área total do município. A área destinada à agricultura continuou em expansão, passando de $22,73 \%$ para $33,99 \%$. A área de mata continuou em regressão, passando de $7,73 \%$ para $5,90 \%$, porém o cerrado teve um crescimento de $8,07 \%$ para $12,86 \%$ (Figura 6). Dessa maneira, durante o período 1989 - 2006 houve acréscimo nas áreas naturais de 15,94\% para $18,83 \%$, enquanto as áreas antropizadas reduziram de $84,06 \%$ para $81,17 \%$, comportamentos opostos ao período 1966 - 1989 (Figura 7).

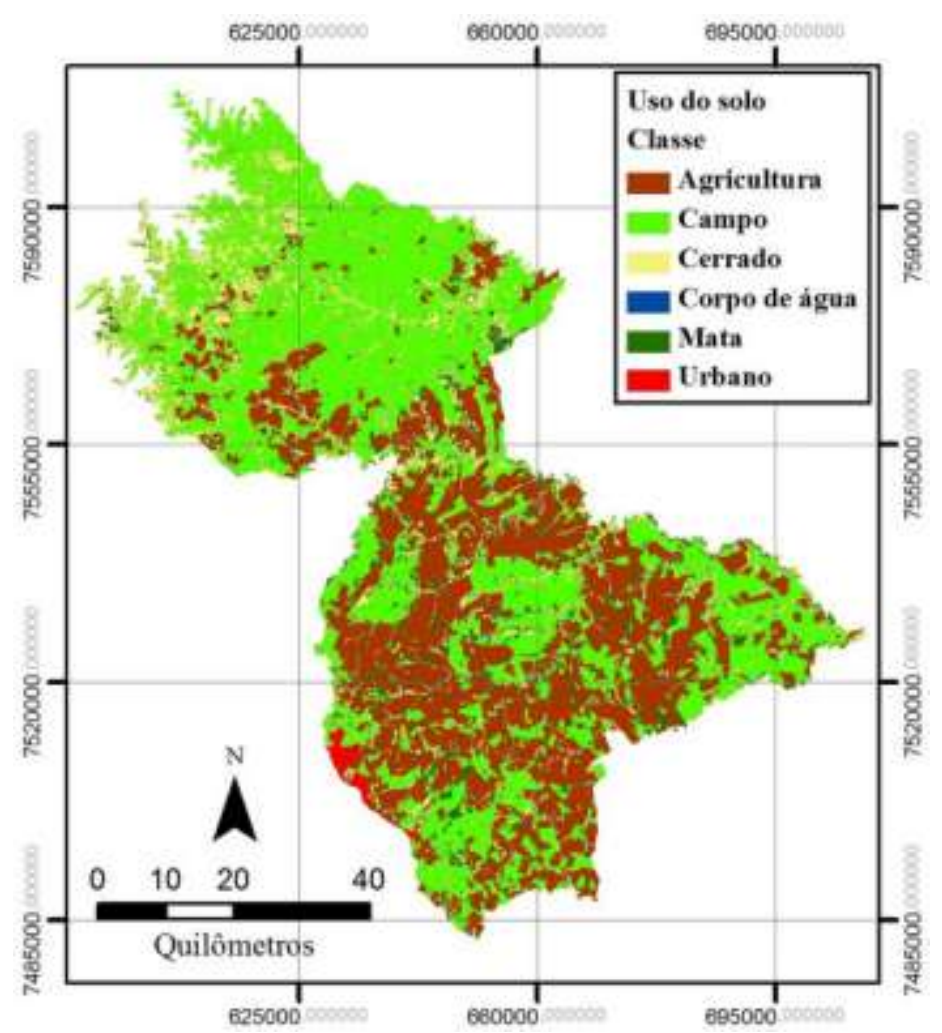

Figura 6. Cobertura do solo de Ponta Porã, 2006. 

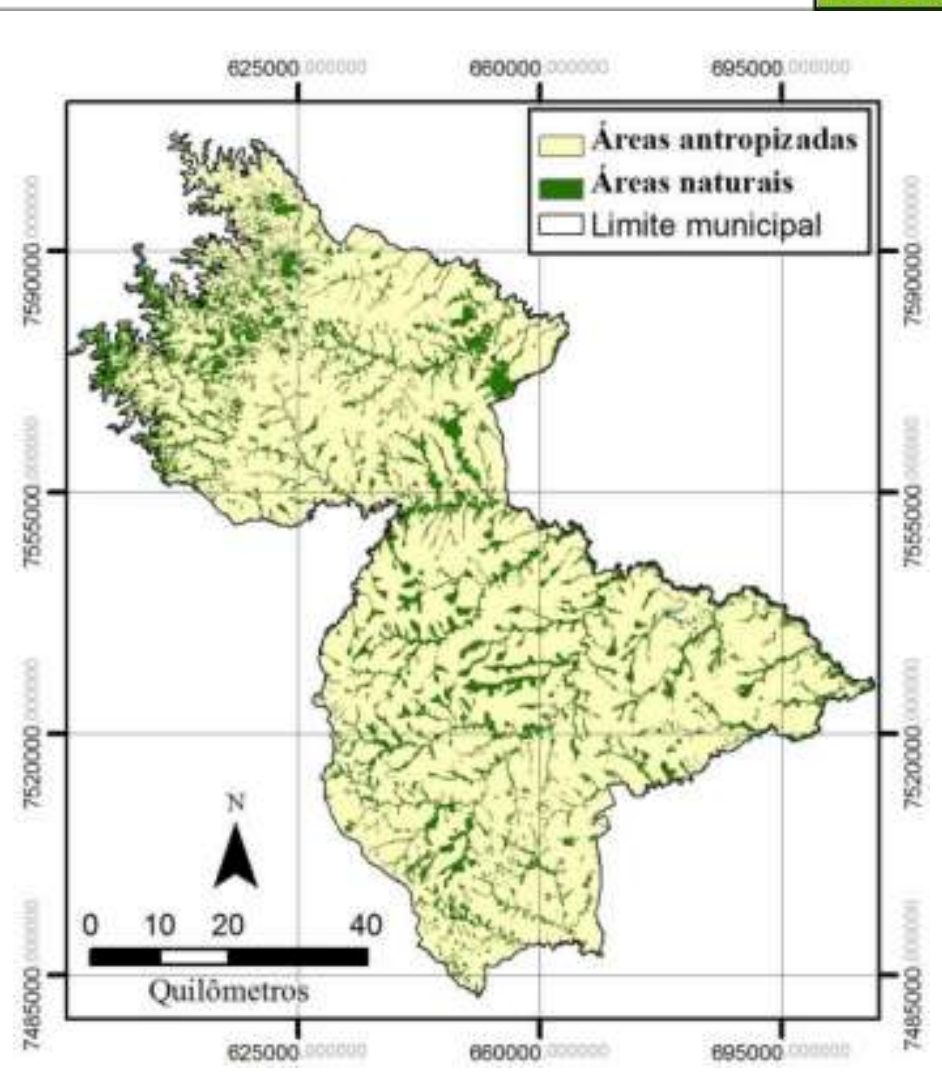

Figura 7. Áreas naturais e antropizadas de Ponta

Porã, 2006.

A alternância de classes de uso do solo e suas respectivas áreas, no município de Ponta Porã, entre 1966 e 2006 pode ser visualizada na Tabela 1. Tais classes de uso foram agrupadas em Áreas naturais e Áreas antropizadas. A evolução desses dois grupos durante o período de estudo pode ser visualizada na Tabela 2.

Tabela 1. Valores de áreas das diferentes classes de cobertura do solo de Ponta Porã, em 1966, 1989 e 2006.

\begin{tabular}{lcccccc}
\hline \multirow{2}{*}{ Classes de uso do solo } & \multicolumn{2}{c}{1966} & \multicolumn{2}{c}{1989} & \multicolumn{2}{c}{2006} \\
& Área $(\mathrm{Ha})$ & $(\%)$ & Área $(\mathrm{Ha})$ & $(\%)$ & Área $(\mathrm{Ha})$ & $(\%)$ \\
\hline Urbano & 394,55 & 0,07 & $2.482,60$ & 0,47 & $2.877,46$ & 0,54 \\
Mata & $74.299,89$ & 13,94 & $41.169,21$ & 7,73 & $31.438,86$ & 5,90 \\
Cerrado & $53.236,32$ & 9,99 & $42.979,71$ & 8,07 & $68.526,07$ & 12,86 \\
Campo & $399.607,71$ & 74,99 & $324.302,56$ & 60,86 & $248.526,88$ & 46,64 \\
Agricultura & $4.150,70$ & 0,78 & $121.112,45$ & 22,73 & $181.119,83$ & 33,99 \\
Corpos de água & $1.172,93$ & 0,22 & 815,57 & 0,15 & 373,00 & 0,07 \\
TOTAL & $532.862,10$ & 100,00 & $532.862,10$ & 100,00 & $532.862,10$ & 100,00 \\
\hline
\end{tabular}




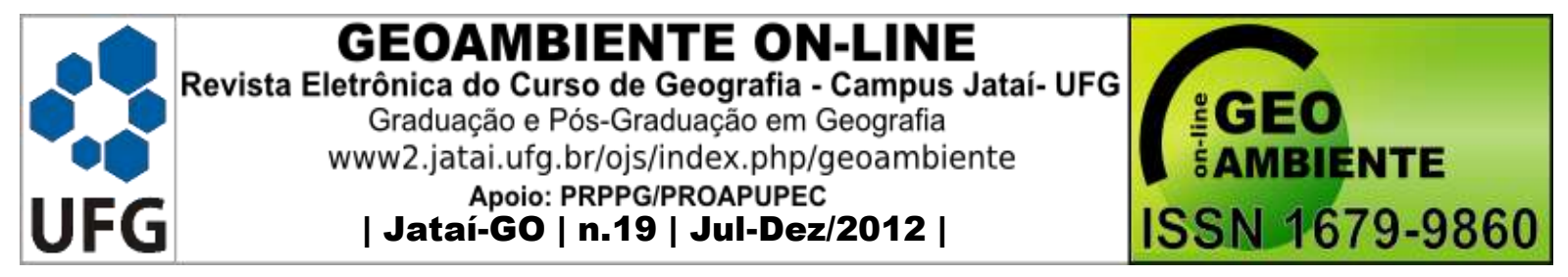

Tabela 2. Evolução das Áreas naturais e antropizadas de Ponta Porã, em 1966, 1989 e 2006.

\begin{tabular}{lcccccc}
\hline \multirow{2}{*}{ Classes } & \multicolumn{2}{c}{1966} & \multicolumn{2}{c}{1989} & \multicolumn{2}{c}{2006} \\
& Área (Ha) & $(\%)$ & Área (Ha) & $(\%)$ & Área (Ha) & $(\%)$ \\
\hline Áreas naturais & $128.709,13$ & 24,15 & $84.964,49$ & 15,94 & $100.337,93$ & 18,83 \\
Áreas antrópicas & $404.152,97$ & 75,85 & $447.897,61$ & 84,06 & $432.524,17$ & 81,17 \\
TOTAL & $532.862,10$ & 100 & $532.862,10$ & 100 & $532.862,10$ & 100 \\
\hline
\end{tabular}

\section{Conclusões}

Este estudo apresenta dados quantitativos do que já se conhecia qualitativamente na história de ocupação do Município de Ponta Porã, desde o tempo de conflito pela fronteira com o Paraguai, passando de áreas de pastagens e campos para a agricultura, na chegada dos imigrantes do Rio Grande do Sul. O fluxo migratório para Ponta Porã e o avanço da agricultura mecanizada associada à soja, trigo e milho, nas décadas de 1970 e 1980 ocasionou o avanço significativo nas áreas ocupadas por atividades agrícolas.

Este mesmo fluxo migratório também é responsável pela redução das grandes áreas utilizadas para pastagens, o aumento da área urbana, a redução dos corpos de água e a redução das áreas naturais. Hoje a realidade são os assentamentos, um novo tipo de ocupação onde se encontram pequenas propriedades e grande heterogeneidade na ocupação.

A análise temporal, aplicada neste estudo, possibilitou deduções diretas e pontuais quanto às mudanças no uso e ocupação do solo de Ponta Porã e sobre o estado de preservação dos elementos que compõem a paisagem do município.

Este trabalho apresenta a evolução do uso do solo de Ponta Porã, através de metodologias aplicáveis e úteis em modelos para estudos ambientais, o que possibilita propor meios para mitigar as degradações ambientais, tomando ações concretas quanto ao melhor manejo dos solos e buscar alternativas mais viáveis, com ênfase no cuidado nas práticas de manejo e conservação dos solos.

\section{Referências Bibliográficas}

AVENZA SYSTEMS: MaPublhisher. Version 4.0. Avenza Systems Inc. 2001. 1CD-ROM. BONES, S.M. Avaliação do Plano de Desenvolvimento do Assentamento Itamarati (PDA): um estudo de caso. 2006. 140f. Dissertação de Mestrado. Universidade Federal de Mato Grosso do Sul, Departamento de Economia e Administração. 2006. 


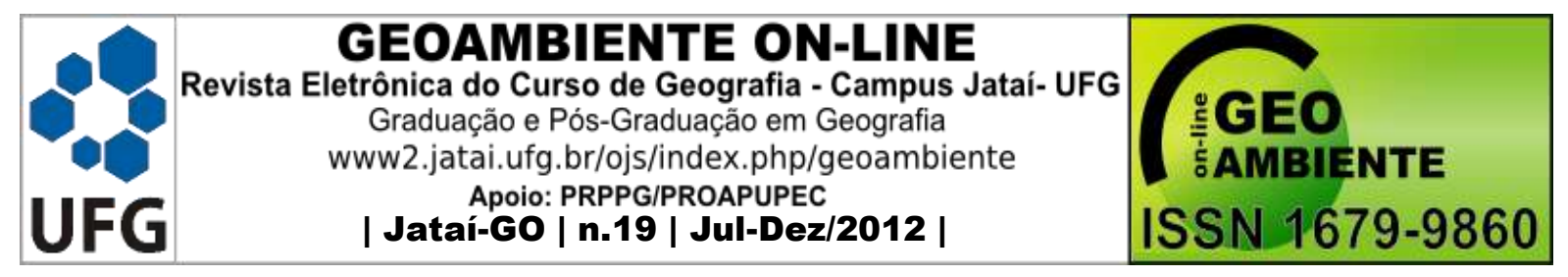

CARRIJO, M. G. G. Vulnerabilidade Ambiental: o caso do Parque Estadual das Nascentes do Rio Taquari. 2005. 112f. Dissertação de mestrado. Programa de Pós-Graduação em Tecnologias Ambientais. UFMS. 2005.

CORINE: CORINE Land Cover. Coordination of Information on the Environment. $106 f$. Comm of European Communities, Bruxelas, 1992.

DSG - Diretoria do Serviço Geográfico Brasileiro. Carta Antonio João. Folha SF. 21-Z-AIII. Ministério do Exército - Região Centro-Oeste do Brasil - Diretoria do Serviço Geográfico Brasileiro. Carta. 1966a. Escala 1:100.000.

DSG - Diretoria do Serviço Geográfico Brasileiro. Carta Bocajá. Folha. SF. 21-Z-B-VI. Ministério do Exército - Região Centro-Oeste do Brasil - Diretoria do Serviço Geográfico Brasileiro. Carta. 1966b. Escala 1:100.000.

DSG - Diretoria do Serviço Geográfico Brasileiro. Carta Boqueirão. Folha SF. 21-X-C-V. Ministério do Exército - Região Centro-Oeste do Brasil - Diretoria do Serviço Geográfico Brasileiro. Carta. 1966c. Escala 1:100.000.

DSG - Diretoria do Serviço Geográfico Brasileiro. Carta Campestre. Folha SF. 21-Z-A-II. Ministério do Exército - Região Centro-Oeste do Brasil - Diretoria do Serviço Geográfico Brasileiro. Carta. 1966d. Escala 1:100.000.

DSG - Diretoria do Serviço Geográfico Brasileiro. Carta Dourados. Folha SF. 21-Z-B-II. Ministério do Exército - Região Centro-Oeste do Brasil - Diretoria do Serviço Geográfico Brasileiro. Carta. 1966e. Escala 1:100.000.

DSG - Diretoria do Serviço Geográfico Brasileiro. Carta Maracaju. Folha SF. 21-X-D-IV. Ministério do Exército - Região Centro-Oeste do Brasil - Diretoria do Serviço Geográfico Brasileiro. Carta. 1971a. Escala 1:100.000.

DSG - Diretoria do Serviço Geográfico Brasileiro. Carta Ponta Porã. Folha SF. 21-Z-A-VI. Ministério do Exército - Região Centro-Oeste do Brasil - Diretoria do Serviço Geográfico Brasileiro. Carta. 1971b. Escala 1:100.000.

DSG - Diretoria do Serviço Geográfico Brasileiro. Carta Vista Alegre. Folha SF. 21-X-CVI. Ministério do Exército - Região Centro-Oeste do Brasil - Diretoria do Serviço Geográfico Brasileiro. Carta. 1971c. Escala 1:100.000.

ERDAS: Erdas Imagine. Version 8.3.1. Erdas Inc. Atlanta-Geórgia. 1997. 1 CD ROM. 


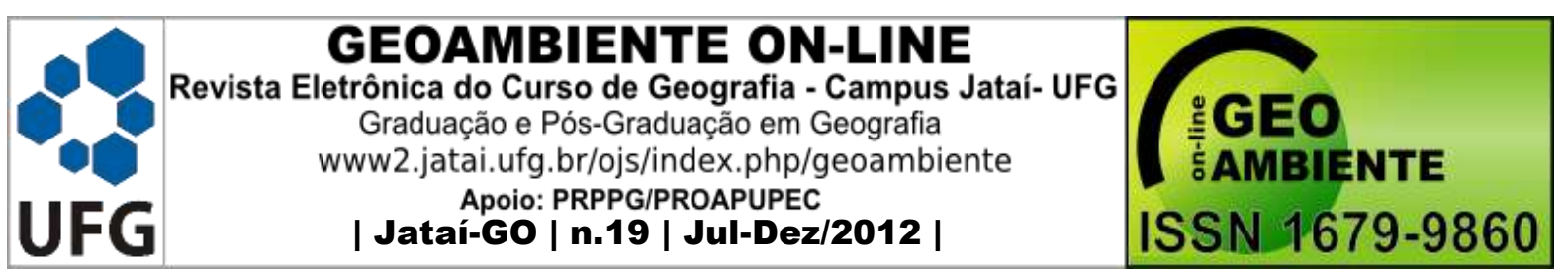

FRANCO, F. S.; COUTO, L.; CARVALHO, A.F., JUCKSCH, I.; FILHO, E. I. F.; SILVA, E.; MEIRA NETO, J. A. A. Quantificação de erosão em sistemas agroflorestais e convencionais na Zona da Mata de Minas Gerais. Revista Árvore, Viçosa, MG. v. 26, n. 6, p.751-760, 2002.

GRIGIO, A. M. Aplicação do sensoriamento remoto e sistemas de informação geográfica na determinação da vulnerabilidade natural e ambiental do Município de Guaramé (RN): simulação de risco às atividades da indústria petrolífera. 2003. 230f. Dissertação (mestrado). Universidade Federal do Rio Grande do Norte. 2003.

GRIGIO, A. M. Evolução da Paisagem do Baixo Custo do Rio Piranhas-Assu (1988-2024): Uso de Autômatos Celulares em Modelo Dinâmico Espacial para Simulação de Cenários Futuros. 2008. 250 f. Tese (doutorado). Programa de Pós-Graduação em Geodinâmica e Geofísica. Universidade Federal do Rio Grande do Norte. 2008.

INPE - Instituto Nacional de Pesquisas Espaciais. LANDSAT TM. Imagem de satélite. Canais 1,2,3,4,5 e 7. Órbita/Ponto: 225/075. Julho de 2006. Disponível em <http://www.inpe.br> Acesso em dezembro de 2006a.

INPE - Instituto Nacional de Pesquisas Espaciais. LANDSAT TM. Imagem de satélite. Canais 1,2,3,4,5 e 7. Órbita/Ponto: 225/076. Julho de 2006. Disponível em $<$ http://www.inpe.br> Acesso em dezembro de 2006b.

MACROMEDIA: FreeHand. Version 9. Macromedia Inc. 2000. 1 CD ROM.

OLIVEIRA, L. G. L. de. Elaboração e aplicação de modelo digital de elevação: o caso de estudo do Parque Municipal de Costa Rica, MS. 2005. 43 f. Trabalho de Conclusão de Curso (Graduação em Engenharia Ambiental). Universidade Federal de Mato Grosso do Sul. 2005.

PARANHOS FILHO, A. C. Análise Geo-Ambiental Multitemporal: O estudo de Caso da Região de Coxim e Bacia do Taquarizinho. 2000. 213 f. Tese (doutorado). Curso de PósGraduação em Geologia. Universidade Federal do Paraná. 2000.

PARANHOS FILHO, A. C.; LASTORIA, G.; TORRES, T. G. Sensoriamento Remoto Ambiental Aplicado: Introdução as Geotecnias. Campo Grande: Ed. UFMS. 2008. 198p.

PCI GEOMATICS: Geomatica. Versão 9.1 for Windows. 2003. 1 CD-ROM

SANTOS, G. V.; DIAS, H. C. T.; SIlVA, A. P. de S.; MACEDO, M. N. C. de. Análise hidrológica e socioambiental da bacia hidrográfica do córrego Romão dos Reis. Revista Árvore. Viçosa, v. 31, n.5 [cited 2010-02-09], p. 931-940, 2007. 